\title{
Correction to: Ventral striatal and septal area hypermetabolism on FDG-PET in herpes simplex viral encephalitis
}

\section{T. Singhal ${ }^{1} \cdot$ I. Solomon ${ }^{2} \cdot$ F. Akbik ${ }^{1} \cdot$ S. Smirnakis ${ }^{1} \cdot$ H. Vaitkevicius ${ }^{1}$}

Published online: 12 September 2019

(C) Journal of NeuroVirology, Inc. 2019

\section{Correction to: Journal of NeuroVirology https://doi.org/10.1007/s13365-019-00779-2}

In the case description section, the sentence "A repeat dedicated brain FDG-PET scan performed on day 9, under burst suppression, showed diffuse hypermetabolism with persistent relative hypermetabolism in the left ventral striatum and septalarea (Fig. 1b)." should read as "A repeat dedicated brain FDG-PET scan performed on day 9, under burst suppression, showed diffuse hypometabolism with persistent relative hypermetabolism in the left ventral striatum and septal area (Fig. 1b)."

Publisher's note Springer Nature remains neutral with regard to jurisdictional claims in published maps and institutional affiliations.

The online version of the original article can be found at https://doi.org/ $10.1007 / \mathrm{s} 13365-019-00779-2$

T. Singhal

tsinghal@bwh.harvard.edu; tsinghal@partners.org

1 Department of Neurology, Brigham and Women's Hospital, Harvard Medical School, Building for Transformative Medicine, Room 4092, 60 Fenwood Road, Boston, MA 02115-6128, USA

2 Department of Pathology, Brigham and Women's Hospital, Harvard Medical School, Boston, MA, USA 